\title{
ASSESSMENT
}

\section{Examining Undergraduate Student Outcomes from a Community-Engaged and Inquiry-Oriented Capstone Experience}

Michelle Samura, Chapman University

\begin{abstract}
Although educational research indicates that undergraduate student participation in research, fieldwork, and/or community engagement has great value, there remains a dearth of information on student outcomes from participation in these activities. Drawing on high-impact educational practices as the conceptual framework, this article examines self-reported outcomes from participants in an intensive, one-year capstone experience for fourth-year students that was composed of fieldwork and research. Qualitative analysis of end-of-semester student reflections indicated that research primarily contributed to students' academic development, fieldwork contributed to professional development, and the capstone course contributed to the personal and social development of students. Findings suggest that the combination of highimpact practices in a capstone experience may lead to the development of more engaged, prepared, and proactive professionals and citizens.
\end{abstract}

Keywords: capstone experience, college student development, fieldwork, high-impact educational practices, undergraduate research

\section{doi: 10.18833/spur/1/3/15}

Institutions of higher education are reevaluating and redefining their role in society. As colleges and universities balance the preparation of students for relevant careers on the one hand and contributions to a greater common good on the other, updated strategies and structures are needed to support these efforts. The value of inquiryoriented, community-engaged learning for undergraduate students has become increasingly apparent, particularly educational experiences that enable students to connect coursework with real-world issues and combine personal interests with career opportunities and community needs. In fact, research, fieldwork, and community engagement have been identified as "high-impact educational practices" correlated to student success (Association of American Colleges \& Universities 2007). More specifically, firstyear seminars, common intellectual experiences, learning communities, writing-intensive courses, collaborative projects, undergraduate research, diversity and global learning, service learning and community-based learning, internships, and capstone courses are strongly associated with increased student engagement and retention (Cruce et al. 2006; Kuh et al. 2008).

High-impact educational practices are cited as being particularly effective because they facilitate student engagement (Kuh 2008). Students are required to commit time and effort to the activities and interact with people who are different from themselves. High-impact educational practices enable students to interact with faculty and peers in meaningful ways for extended periods of time and receive frequent feedback. These practices are considered particularly impactful because they offer opportunities for students to connect course content with real-world contexts, thus facilitating a meaningful and transformative educational experience.

There is a range of research on the various outcomes of high-impact practices (Kilgo, Sheets, and Pascarella 2015; Bonet and Walters 2016). Using data from the College Student Experiences Questionnaire (Pace and Kuh 1998), Hu, Kuh, and Li (2008) examined how students' participation in inquiry-oriented activities affected various outcomes, 
such as their learning and personal development. The researchers found that student engagement in inquiryoriented activities had an overall positive effect on students, but the effects varied by outcome. For example, although students experienced gains in intellectual development, which included writing clearly, thinking analytically, and presenting ideas effectively, $\mathrm{Hu}$ and colleagues found that participation in inquiry-oriented activities were negatively associated with personal development, including learning to adapt to change and developing a greater understanding of self and individual abilities. The researchers concluded that more research is needed on the effects of different types of undergraduate inquiry-oriented educational experiences on various student outcomes.

A small body of research has focused on identifying student outcomes from participation in a combination of high-impact practices (Gilardi and Lozza 2009). For example, Gilardi and Lozza (2009) addressed the lack of attention dedicated to possible connections between undergraduate research activities and students' professional goals by exploring the development of students' professional skills through inquiry-oriented teaching and learning activities. The researchers examined the Università Cattolica of Milan's Practical Experience of Internship course, which is designed to develop students' professional identities through field research projects. Based on analysis of student-written narratives, self-report questionnaires, and final reports produced by groups, Gilardi and Lozza identified several conditions that seemed to facilitate student attainment of the course's goals. In particular, opportunities for students to give and receive timely and frequent feedback from instructors and peers, actively participate in knowledge generation and dissemination, and frequently reflect on experiences contributed to students' development of professional identities.

In their review of the research literature on high-impact educational practices, Brownell and Swaner (2009) concluded that much has been written about learning communities, undergraduate research, first-year seminars, and service learning, but many publications have remained limited to "descriptive and prescriptive pieces talking about program elements" (2009, 26). Brownell and Swaner also found that researchers paid little attention to capstone experiences in the years leading up to their literature review and that there was little to no research focused on student outcomes. Essentially, there has been limited empirical research on student outcomes associated with capstone courses, internships, common intellectual experiences, and writing-intensive courses (Kilgo et al. 2015).

Despite the body of research that clearly indicates the promise of high-impact educational practices (Cruce et al. 2006; Kuh et al. 2008), there remains a dearth of information on student outcomes from participation in various combinations of these activities (Hu et al. 2008; Kuh 2008). Addressing this gap, this article draws on the high-impact educational practices of the Association of American Colleges and Universities as the conceptual framework to analyze and present findings on outcomes for students in the Integrated Educational Studies (IES) program's capstone experience for fourth-year students at Chapman University. The combination of inquiry-oriented activities, fieldwork, and capstone projects that are embedded in the IES capstone experience offers insight into program structures that can facilitate both engaged learning and community engagement and also facilitate academic, professional, personal, and social development among students.

\section{Integrated Educational Studies (IES) Program}

Launched in fall 2010, IES is the only undergraduate major offered by the Attallah College of Educational Studies at Chapman University — a medium-size, private university in Orange, California. The program challenges students to think boldly and broadly about what it means to be "educators" in the twenty-first century. To prepare students for various aspects of education, the program offers an interdisciplinary curriculum with two emphases: schools and community. Students in the schools' emphasis typically pursue careers in K-12 settings. Students in the community emphasis tend to pursue careers in nonprofit organizations, higher education, policy, afterschool programs, and human resources. Both emphases require the same core courses that are intended to provide students a socio-historical perspective of schools in society.

During their final year in the program, IES majors engage in a culminating capstone experience. The rigorous capstone is composed of two classes taken consecutively: Inquiry, Evidence, and Decision-Making (IES 405) and Senior Capstone Seminar (IES 492). During IES 405, students begin research projects, also referred to by IES faculty and students as "inquiry projects," by selecting a topic or an issue in which they are interested and want to understand more deeply. Over the years, students have engaged research on a broad range of topics such as corporate social responsibility within professional sports organizations, opportunities and challenges of inclusive education, dual-immersion schooling, and the development of "scientist identities" among girls in elementary school. In both IES 405 and 492, students learn several research methods, including literature reviews, interviews, participant observation, media analysis, and are given opportunities to engage in fieldwork so they may examine their inquiry topics through multiple perspectives.

As part of their inquiry projects, students are required to complete a minimum of 60 hours at a fieldwork site during IES 492. Students are encouraged to choose sites that closely align with their career interests. Students 
also develop an electronic portfolio during IES 492 that demonstrates their growth and development over time as educators and specifically addresses how they have met IES program learning outcomes. The first group of IES majors to complete the full program graduated in May 2014. Thus, student outcomes still are being identified because the program is relatively new. Currently, selfreported student outcomes of the capstone experience can be examined.

\section{Research Methodology}

The guiding research question for this study was the following: what student outcomes occur from participation in a combination of capstone, research, and fieldwork? Data were collected from students in the author's IES 405 and 492 classes at the end of each semester. Through a paperbased questionnaire, students were asked to respond to the following questions: (1) What have you learned? and (2) What are you taking away from our time together? Findings presented in this article are from seven cohorts of students who completed the one-year IES capstone experience. A total of 139 students were in the author's IES 405 classes and 117 in her IES 492 classes from fall 2012 to spring 2016. The majority of students were women. Responses from both IES 405 and IES 492 questionnaires were analyzed, with the exception of the IES 405 cohort from fall 2013, which has incomplete data.

Most research on high-impact educational practices utilizes large-scale survey data. Although this approach enables researchers to gain a broad view of student outcomes, the range of student perspectives and experiences with different aspects of high-impact educational practices are less clear. The use of open-ended qualitative surveys helps uncover some of the perceptions, processes, and nuances of student experiences that survey data may overlook.

Inductive analysis was used, which involved coding processes and constant comparative analysis, from the analytical tradition of grounded theory (Strauss and Corbin 1994). A three-step coding process was employed of open coding, axial coding, and selective coding (Babbie 2013; Strauss and Corbin 1998). The inductive process enabled emergent patterns to be identified. Units of analysis were separated by topics. During open coding, labels were assigned to each topic that emerged in students' responses. Examples of open codes include greater understanding of self, career clarification, and greater understanding of evidence-based decisions. After connections among open codes were examined, axial codes were identified.

Next, open codes were categorized by high-impact educational practice to see whether students' responses could be organized under one or two high-impact educational practices. This step also enabled an assessment of possible alignment of axial codes with high-impact educational practices. For example, students' development of research skills was categorized under both "capstone courses" and "undergraduate research." Finally, another pass at students' responses provided examples of emergent themes.

\section{Findings and Discussion}

Four types of student outcomes emerged from the data: (1) academic development, (2) personal development, (3) professional development, and (4) social development. Academic development included student growth in research methods and academic writing, increased understanding of the specific topic or issue around which their capstone project was based, and a deepened understanding of the value and utility of research and evidence-based decision making. Personal development included students' feeling a sense of accomplishment, greater confidence, deeper understanding of self, and the ability to monitor personal and intellectual growth. Also included in personal development was students' ability to more effectively manage uncertainty. Professional development included responses about career clarification, professionalization, improved public speaking and presentation skills, ability to write for different audiences, and enhanced organization and time management skills. Finally, social development included students feeling a sense of community with peers, understanding the value of peer support, and acquiring improved collaboration skills.

When these four types of student outcomes were further categorized under the three high-impact educational practices embedded in the IES capstone experience, it became clear that each high-impact educational practice contributed to one student outcome area more than others. The most prominent student outcome for undergraduate research was academic development. For fieldwork, students indicated the greatest growth in professional development. Capstone courses/projects were most closely connected with students' personal and social development (see Table 1).

\section{Outcomes for Undergraduate Research and Inquiry-Oriented Activities}

The majority of students in the IES capstone courses cited learning specific research skills, such as conducting literature reviews, engaging in participant observation, conducting interviews, deconstructing media, and analyzing data. Students also emphasized how through their undergraduate research experience they developed and strengthened their ability to think critically and support their ideas with data. For example, when asked what she is taking away from the research aspect of her capstone experience, Maura explained: "Something that I am taking away from this class is knowing how to do deep analysis. Now I have the tools and resources and therefore will have credibility rather than just base my points and key themes based on my personal interpretation." 
TABLE 1. Student Outcomes for High-Impact Educational Practices in the IES Capstone Experience

\begin{tabular}{|c|c|c|}
\hline High-impact practice & Primary student outcomes & Secondary student outcomes \\
\hline \multirow[t]{2}{*}{$\begin{array}{l}\text { Undergraduate research and } \\
\text { inquiry-oriented activities }\end{array}$} & \multirow{2}{*}{$\begin{array}{l}\text { Academic development } \\
\text { - Research skills } \\
\text { - Appreciation of research; understand the value } \\
\text { of research and evidence-based decisions } \\
\text { - Learned more about specific inquiry/research } \\
\text { topic } \\
\text { - Interest in research } \\
\text { - Writing skills }\end{array}$} & $\begin{array}{l}\text { Personal development } \\
\text { - Sense of completion; sense of accomplishment } \\
\text { - Able to more effectively manage the unexpected; } \\
\text { how to be flexible }\end{array}$ \\
\hline & & $\begin{array}{l}\text { Professional development } \\
\text { - Organization and time management skills } \\
\text { - Writing skills; writing for different audiences }\end{array}$ \\
\hline \multirow[t]{2}{*}{ Fieldwork } & \multirow{2}{*}{$\begin{array}{l}\text { Professional development } \\
\text { - Organization and time management skills } \\
\text { - Career clarification } \\
\text { - Professionalization }\end{array}$} & $\begin{array}{l}\text { Academic development } \\
\text { - Learned more about specific inquiry/research topic }\end{array}$ \\
\hline & & $\begin{array}{l}\text { Personal development } \\
\text { - Able to more effectively manage the unexpected; } \\
\text { how to be flexible }\end{array}$ \\
\hline \multirow[t]{2}{*}{ Capstone courses/projects } & $\begin{array}{l}\text { Personal development } \\
\text { - Sense of completion; sense of accomplishment } \\
\text { - Confidence; greater understanding of self; ability } \\
\text { to monitor personal and intellectual growth } \\
\text { - Importance of being reflective; opportunities to } \\
\text { reflect }\end{array}$ & $\begin{array}{l}\text { Academic development } \\
\text { - Research skills } \\
\text { - Learned more about specific inquiry/research topic }\end{array}$ \\
\hline & $\begin{array}{l}\text { Social development } \\
\text { - Sense of community with classmates; support; } \\
\text { collaboration skills }\end{array}$ & $\begin{array}{l}\text { Professional development } \\
\text { - Organization and time management skills } \\
\text { - Public speaking and presentation skills } \\
\text { - Writing skills; writing for different audiences }\end{array}$ \\
\hline
\end{tabular}

Similarly, Katrina shared, "I am taking away the ability to deeply analyze and justify why I am doing what I am doing. In research you always have a reason and justification behind your actions. This is the first class that really challenged my reasoning." Cate also stated that she was leaving the class with "a way to critically view the world from multiple perspectives and seek out answers myself. Creative problem solving."

The skills gained from students' research projects aligned with findings from the study of $\mathrm{Hu}$ and colleagues (2008) in which the researchers found intellectual development among students who participated in inquiry-oriented activities. Students in their study self-reported gains in critical thinking and analysis and increased ability to write and present ideas clearly. However, unlike the findings of $\mathrm{Hu}$ and colleagues, students in the IES capstone experienced professional academic development as well as personal development, including a greater understanding of individual passions and interests, and development of persistence. This may be due to the nature of the IES capstone in which students choose their own inquiry topics as opposed to receiving an assigned one.

Experiences with undergraduate research processes also provide students with new perspectives on learning and helped demystify research processes. Through her inquiry project process that focused on the development of math beliefs in K-12 classrooms, Mica emerged with the following perspective on research:

I think I understand the research process a lot better now, which will make me a better reader/listener whenever I hear about studies... I think the main thing I'm taking away is a sense that research is do-able, and not just something I read about other people doing.

Although academic development was the primary outcome of conducting research, students also experienced important development in the areas of professionalism and personal growth. For example, Maura shared that through her research experience on yoga in school settings, she not only gained research techniques and indepth knowledge on her chosen research topic, but she also further developed her passion for teaching and learning. Maura explained that, as a result of conducting research, she possesses "a much greater understanding of myself and my passions, and confidence." Similarly, Sol shared how her experience with research contributed to a "new sense of confidence in my ability to tackle large difficult assignments."

The value of research experiences spanned beyond skills and knowledge. The research process enabled many students to build self-confidence. Successfully navigating rigorous research processes provided assurance that they could effectively manage difficult work and circumstances in the 
future. These indicators of students' personal development closely related to the professional development they also gained through research experiences. For instance, Madison shared about the particular traits she developed through the research experience: "I am taking away the power of collaboration, how to research, how to observe unbiasedly, how to pay attention to detail, how to value evidence-based decisions, how to continue to push myself, how to be reflective." The skills, traits, and dispositions cultivated through research processes significantly contribute to students' academic development, in addition to their personal and professional development.

\section{Fieldwork Outcomes}

Fieldwork for students in the IES capstone is a combination of two high-impact educational practices: internships and community-based learning. Although research typically views these high-impact educational practices as separate, with one focused more on career-related experiential learning and the other focused on application of coursework to real-life settings, both activities are part of the IES capstone. Students find fieldwork sites that mirror the profession in which they are interested. Their experiences at these fieldwork sites are designed to support the work in the organizations. During their capstone experience, students are required to spend a minimum of 60 hours at a fieldwork site during IES 492, and their self-chosen fieldwork site often is a stepping-stone to a future career.

The primary student outcome from fieldwork in the IES capstone experience was professional development. A number of other students also emphasized the value of fieldwork for clarifying career aspirations and the skills and perspectives needed to be successful in their chosen fields. Having spent time in a high school math class, Audra stated, "I have learned a lot about myself and my career goals. I have also learned professional development skills such as communicating effectively with professionals in my field and how to present myself professionally."

Lara highlighted the connections between their fieldwork and research experiences and how insights gained through both processes informed her professional development. She shared: "The dedication all the students have for their topic as well as the chance I had to research my topic in depth. This class also allowed me to/motivated me to step closer to the career I want by making connections to the field." The outcomes of participation in fieldwork by IES students were similar to what existing research have found-namely, improved interpersonal skills (Parker et al. 2016; Simons et al. 2012). Simons and colleagues (2012) found that students who participated in an undergraduate psychology internship program experienced improvement in their cultural competence and enhanced their knowledge of the field as well as the professional skills (e.g., time management) needed to thrive in their chosen profession. For IES students, however, it seemed to be the combination of inquiry-oriented activities and fieldwork that resulted in students experiencing professional, academic, and even personal development. The academic and personal development occurred because students were able to situate their research with real-world settings and in ways that connected students with communities with whom they desire to work. Emma's inquiry project was on the impact of 1-to-1 iPad implementation in high school classrooms. She explained:

Not only have I learned so much about iPads in the classroom, I learned also about research and different methods and how to be a good observer. Everything we learned in 405 I was able to actually implement and learn how to actually DO. That's not something most people can take away from a class. (emphasis in original)

Opportunities to conduct research and apply research in real-world settings were invaluable. It enabled students to see firsthand what mattered to people. In Emma's case, it was as a result of being in classrooms in which teachers were learning how to implement technology, particularly iPads, that she realized the need for understanding the potential outcomes of iPad implementation. These findings suggest that there not only is value in participation in individual, high-impact educational practices but also, when practices are combined, students may be able to experience multiple levels and types of development. Student outcomes from a combination of high-impact educational practices can be seen in IES students' reflections on the capstone experience.

\section{Outcomes for Capstone Experiences}

Capstone courses are culminating experiences that typically occur during students' final years in college and involve students completing a project that incorporates and applies what they have learned (Kuh 2008). Examples of capstone projects include portfolios, exhibits, and research papers. The IES capstone experience is unique in that it includes typical capstone elements but also includes extensive fieldwork and research processes. As a result of the combination of multiple high-impact educational practices, students experienced outcomes that span all four types of development. For the IES students in this study, the two most salient outcomes were personal and social development.

Sara explained, "[I] learned the importance of having a specific purpose for everything I say, do, and write" (academic development), and "I have learned to hold myself to higher standards and to challenge myself" (social development). In addition to clarifying professional aspirations, students also emphasized how the capstone experience enabled them to reflect on their undergraduate education and where they were heading next. Jana shared: 
I'm by no means an expert in my topic but I've gained a lot of confidence through this course, which is the most rewarding thing for me. I really used my time management skills more in this class than any other which has given me time to reflect on what I've learned and review it. I didn't realize before how valuable reflection is in the process.

The capstone experience pushed students to take ownership of their own learning. Maura expressed how she was pleased she was with the work she accomplished in the capstone, particularly the comprehensive research paper she wrote. "I have never spent so much time on one assignment," she explained. In the IES capstone, students spent the entire year examining a topic or issue in depth and were required to do multiple drafts of papers. The revision process forced students not to settle for first drafts and challenged them to further own their learning and inquiry process. These insights align with previous research that suggests that capstone experiences are "a significant, positive predictor for inclination to inquire and lifelong learning" (Kilgo et al. 2015, 521). However, the researchers also found that participation in a capstone experience was not a significant predictor for any other outcome measure. Unlike the findings of Kilgo and colleagues, IES students identified a number of other outcomes from their participation in the IES capstone, particularly as a result of the combination of fieldwork, capstone experience, and inquiry-oriented activities.

The fieldwork aspect of the IES capstone was full of unpredictability and unexpected outcomes. At times, students had difficulty finalizing a fieldwork placement or finding a site that seemed to best fit their inquiry topic and their career aspirations. Engaging in these uncertain processes facilitated students' personal development. Students learned how to navigate difficult situations and circumstances outside of their control. This was an important outcome for many of them. When asked about what she learned in the capstone, Jackie simply stated: "That everything you are interested in pursuing might lead you unexpected places or even disappoint you, and that's okay." Similarly, Lauryn shared, "I have learned how to effectively conduct research, set up and go through with internships, learned to adjust to a situation when things don't go according to plan."

During IES 492, students create an electronic portfolio in which they demonstrate and highlight distinctive knowledge, skills, and insights gained throughout their undergraduate experience. Students are required to draw on relevant coursework, fieldwork, and personal experiences as evidence of their growth and development over time in the IES program learning outcomes. Together with their fieldwork and research, the process of analyzing and reflecting upon their own growth contributes in powerful ways to their personal development. Rita shared the following about her self-analysis process: "Recognized my learning, growth and development in the last four years at Chapman. That I can really do hard work and be pushed past what I'm comfortable with, and be successful." Similarly, Art explained about what he gained from the portfolio process: "I have been able to evaluate myself from past experiences. By doing this I was able to develop a better understanding of myself and the work I have over the past four years."

Closely related to students' personal development was their social development. Many students commented on how they experienced firsthand, sometimes for the first time, the deep value of working closely with others, valuing one another's perspectives and opinions, and being open to feedback and even criticism from peers. Jana wrote, "I enjoyed working with this class and seeing everyone's different passions through their capstone projects. Seeing their passion makes me even more excited." Similarly, Joy expressed, "I am taking away the importance of working with others. This class has shown me the value in using other people for connections, feedback, advice, and so much more." Sophia stated, "I thoroughly enjoyed this class and the true sense of community and camaraderie that we all created."

Mira simply stated that her primary takeaway from the IES capstone was "how I can utilize my peers in the world of education." In a class discussion, she further explained what she meant by this statement. As an aspiring elementary school teacher, Mira was excited and encouraged to learn about the diverse interests and professional aspirations held by her peers, a number of whom were pursuing other forms of careers in education such as school counselors, speech pathologists, occupational therapists, and theater directors. She shared how she felt assured heading into her chosen profession knowing that she had peers on whom she could draw as well as support. Mira also explained how, through the community that was developed through the IES capstone experience, she more fully understood the importance and value of integrated and interdisciplinary approaches to education.

Each practice elicited valuable student outcomesacademic development through undergraduate research, professional development through fieldwork, and personal and social development through the capstone courses. It also is possible that the combination of the three highimpact activities in the capstone further compounded the impact. Similar to the account of Gilardi and Lozza (2009) of their undergraduate inquiry-based course that involves fieldwork, IES students gained a great deal from their capstone as a result of active participation in knowledge generation, opportunities to reflect, and frequent 
feedback from both instructors and peers. IES students offered specific ways in which the fieldwork, research, and capstone experiences contributed to their development across multiple dimensions.

\section{Implications for Practice and Research}

Findings from this study confirm insights from existing research on the deep impact of research, fieldwork experiences, and capstone courses for undergraduate students. In addition to providing support for the use of high-impact educational practices, the insights gained from students' reflections on the specific types of outcomes can help other institutions consider how to integrate these proven activities into their own programs. In particular, programs can consider how practices can be combined, in thoughtful and intentional ways, so as to provide more opportunities for students to engage in such transformative activities. Kuh (2008) contends that it is ideal for undergraduate students to participate in a minimum of two high-impact educational practices during their educational experience. If programs can identify ways to combine practices and build them into required curriculum, such as a capstone experience, student participation will increase.

Based on findings from this study, more research is needed on the various types and levels of outcomes from combinations of high-impact educational practices. Future research should examine how different combinations of high-impact educational practices may facilitate different outcomes, as well as different outcomes for different students. For example, the combination of fieldwork and inquiry-oriented activities may be particularly effective when integrated into a capstone experience, since, as this study found, each of these three practices facilitated different primary student outcomes: professional development, academic development, and personal and social development respectively. Further research that uses multi or mixed methods also would be valuable so as to capture both larger patterns and specific nuances of student experiences.

One aspect of this research not initially considered was how the outcomes of all three experiences might be experienced differently depending on student demographics in different fields and disciplines. Findings from this study suggest that students, the majority of whom were women, emerged with greater confidence in their abilities and skills and even developed and embraced researcher identities. For some fields, this development may not be notable. For education - a field in which women often compose the majority of the student population-experience with high-impact educational practices may be an important way to help students develop a broader range of skills, attitudes, and dispositions in even more effective ways. Future research should consider if high-impact educational practices have a more profound impact on students from traditionally underrepresented groups, including women and racial minorities, and if there are particular fields in which such practices may be greatly needed.

Finally, research is needed on the effects of high-impact educational practices on other constituents, namely faculty and community partners. Although faculty generally are supportive of high-impact educational practices, they may hold mixed views of the benefits of these practices for all students. Gaining insight into faculty perspectives, concerns, and needs regarding the integration of high-impact educational practices into the curriculum and their teaching practices will enable institutions of higher education to better support their faculty and ensure the practices are effectively instituted. Research on the impact of high-impact educational practices on the broader community (such as fieldwork partners) also would be useful for understanding the effect of practices beyond student experiences. As mutually beneficial aspects of high-impact educational practices are identified and confirmed, the impetus to integrate these activities in more frequent and consistent ways throughout students' undergraduate experiences will be greater for institutions of higher education and their surrounding communities. Despite the significant body of research on the promise and value of high-impact educational practices, there still is more work to be done to clarify the impact of these activities. Doing so will not only strengthen community and university collaborations but also develop more engaged, prepared, and proactive professionals and citizens.

\section{References}

Association of American Colleges and Universities. 2007. College Learning for the New Global Century: A Report from the National Leadership Council for Liberal Education \& America's Promise. Washington, DC: Author. doi: 10.1111/j.14679647.2008.00458.x

Babbie, Earl. 2013. The Basics of Social Research. 6th ed. Boston: Cengage Learning.

Bonet, Giselle, and Barbara R. Walters. 2016. "High Impact Practices: Student Engagement and Retention." College Student Journal 50: 224-235.

Brownell, Jayne E., and Lynn E. Swaner. 2009. "High-Impact Practices: Applying the Learning Outcomes Literature to the Development of Successful Campus Programs." Peer Review 11(2): 26 .

Cruce, Ty M., Gregory C. Wolniak, Tricia A. Seifert, and Ernest T. Pascarella. 2006. "Impacts of Good Practices on Cognitive Development, Learning Orientations, and Graduate Degree Plans during the First Year of College." Journal of College Student Development 47: 365-383. doi: 10.1353/csd.2006.0042

Gilardi, Silvia, and Edoardo Lozza. 2009. "Inquiry-Based Learning and Undergraduates' Professional Identity Development: Assessment of a Field Research-Based Course." Innovative Higher Education 34: 245-256. doi: 10.1007/s10755-009-9109-0 
$\mathrm{Hu}$, Shouping, George D. Kuh, and Shaoqing Li. 2008. "The Effects of Engagement in Inquiry-Oriented Activities on Student Learning and Personal Development." Innovative Higher Education 33(2): 71-81. doi: 10.1007/s10755-008-9066-Z

Kilgo, Cindy A., Jessica K. Ezell Sheets, and Ernest T. Pascarella. 2015. "The Link between High-Impact Practices and Student Learning: Some Longitudinal Evidence." Higher Education 69: 509-525. doi: 10.1007/s10734-014-9788-Z

Kuh, George D. 2008. High-Impact Educational Practices: What They Are, Who Has Access to Them, and Why They Matter. Washington, DC: Association of American Colleges and Universities.

Kuh, George D., Ty M. Cruce, Rick Shoup, Jillian Kinzie, and Robert M. Gonyea. 2008. "Unmasking the Effects of Student Engagement on First-Year College Grades and Persistence." Journal of Higher Education 79: 540-563. doi: 10.1080/00221546.2008.11772116

Pace, C. Robert, and George D. Kuh. 1998. College Student Experiences Questionnaire. Bloomington: Indiana University Center for Postsecondary Research and Planning.

Parker, Eugene T. III, Cindy A. Kilgo, Jessica K. Ezell Sheets, and Ernest T. Pascarella. 2016. "The Differential Effects of Internship Participation on End-of-Fourth-Year GPA by Demographic and Institutional Characteristics." Journal of College Student Development 57(1): 104-109. doi: 10.1353/ csd.2016.0012
Simons, Lori, Lawrence Fehr, Nancy Blank, Heather Connell, Denise Georganas, David Fernandez, and Verda Peterson. 2012. "Lessons Learned from Experiential Learning: What Do Students Learn from a Practicum/Internship?" International Journal of Teaching and Learning in Higher Education 24: $325-334$.

Strauss, Anselm, and Juliet Corbin. 1994. "Grounded Theory Methodology." In Handbook of Qualitative Research, ed. N. K. Denzin and Y. S. Lincoln, 273-85. Thousand Oaks, CA: SAGE Publications.

Strauss, Anselm, and Juliet Corbin. 1998. Basics of Qualitative Research: Techniques and Procedures for Developing Grounded Theory. Thousand Oaks, CA: SAGE Publications.

\section{Michelle Samura}

Chapman University, samura@ chapman.edu

Michelle Samura is assistant professor and associate dean for undergraduate education in the Attallah College of Educational Studies at Chapman University. She also is the founding co-director of the Collaborate Initiative. Samura's research focuses on the intersections of space, race, and education. She is particularly interested in how a spatial approach offers a unique lens to more effectively examine varying levels of power and a more accessible language for discussing the related dilemmas.

\section{Did you know?}

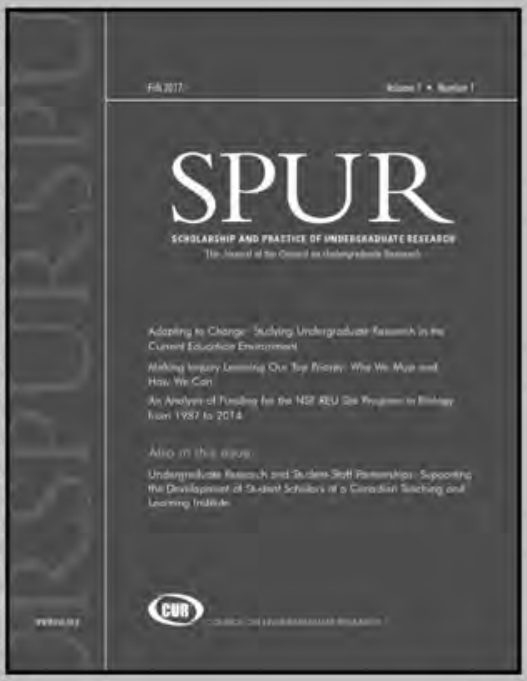

\section{SPUR has an RSS feed for its tables of contents.}

Subscribe at:

https://www.cur.org/ RSS/SPURTOCfeed.xml 